Original Article

\title{
Role of Dexamethasone in Recurrent and Residual Chronic Subdural Hematoma
}

\author{
Syed Aamir shah ${ }^{1}$, Fahmida Arab Mallah², Abdul Razaque Mari², Imran Mirbaher ${ }^{2}$ \\ Hamid Akbar Sheikh², Muzmil Dilbar², Shams Raza Brohi ${ }^{3}$ \\ ${ }^{1}$ Shaheed Zulfiqar Ali Bhutto Medical University (SZABMU), PIMS, Islamabad \\ ${ }^{2}$ Peoples University of Medical and Health Sciences for Women, Nawabshah - Shaheed Benazir Abad \\ ${ }^{3}$ Suleman Roshan Medical College, Tando Adam - Pakistan
}

\section{ABSTRACT}

Objectives: To assess the effectiveness of dexamethasone in recurrent and residual chronic subdural hematoma as a monotherapy.

Material and Methods: A prospective Quasi-Experimental study was conducted at the Neurosurgery Department, Peoples Medical College Hospital, Nawabshah from July 2014 to June 2020.Patients were assessed by Markwalder's neurological grading and intravenous dexamethasone was used as monotherapy and effects were monitored.

Results: Out of 280 patients 100 patients had recurrent and 180 patients had a residual chronic subdural hematoma. Male $n=180$, female $n=100$ with male to female ratio 1.8:1. Patients with Markwalder Grade 0, 1 , and 2 were included and Grade $3 \& 4$ with marked midline shift on plain Computed tomographic scan brain were excluded. Intravenous dexamethasone of $12 \mathrm{mg}$ in three divided doses for 24 hours given for first 2 weeks then shifted on oral dexamethasone and gradually tapered in next 2 weeks. During this period patient was evaluated for fluctuation in blood sugar or epigastric pain. Serial follow-up of patient was done, $16.07 \%$ improved from Markwalder Grade - 2 to 0, Markwalder Grade 1 to 0 in $12.14 \%$. Complete resolution of hematoma occurred in 53.57\%. Radiological deterioration with increased volume of hematoma in $n=40$ and worsening to Markwalder Grad $-3 n=15$ and Grade $-4 n=25$. Death in $n=11$. Ptosis in $n=1$ and focal fits in $\mathrm{n}=3$.

Conclusion: Monotherapy with dexamethasone in recurrent and residual chronic Subdural Hematoma results in clinical improvement and reduces the rate of re-operation.

Keywords: Dexamethasone, Chronic SDH, Recurrent and residual CSDH, Steroids, Monotherapy.

Corresponding Author: Fahmida Arab Mallah Assistant Professor, Neurosurgery

Peoples University of Medical and Health Sciences

For Women, Nawabshah - Shaheed Benazirabad

Email: fahmidamallah25@hotmail.com
Date of Submission: 16-08-2021

Date of Revision: 01-09-2021

Date of Acceptance: 11-09-2021

Date of Online Publishing: 30-09-2021

Date of Print: 30-09-2021

DOI: $10.36552 /$ pjns.v25i3.587 


\section{INTRODUCTION}

Wepfer in 1656 first time described Chronic Subdural Hematoma (CSDH) as an endomembrane accumulation of blood and its metabolites that encased between dura mater and the arachnoidea. ${ }^{1}$ It is due to rupture of bridging cerebral veins, as a result of trivial trauma in atrophic brain and coagulopathy disorder. Clinical presentation varied from asymptomatic to severe life-threatening conditions and most commonly Markwalder neurological grading is used to assess the status of patients suffering from $\mathrm{CSDH}^{2,3}$

Chronic subdural hematoma is typically considered as an elder population disease with a frequency of (Seven/100,000 people) with a peak age of 70 years. ${ }^{4}$ In around 60 to $80 \%$, the trivial traumatic event is accounted for hemorrhage. ${ }^{5}$ Risk factors for developing chronic SDH are Alcoholism; concomitant; illnesses like hepatic disease, renal dysfunction, diabetes mellitus, brain atrophy, usage of anti-clotting anti-aggregates, and presence of a ventriculoperitoneal shunt. Somehow Pathophysiology of $\mathrm{CSDH}$ is still not very well understood. ${ }^{6,7}$

Recently few published research had mentioned detailed ultra-structural meningeal and neo-membrane anatomy with the formation of hematoma, pro-inflammatory, fibrinolytic, angiogenic, and coagulation-cascade factors. ${ }^{8}$ As of now, CSDH is better explained as a persistent self-propagating inflammatory method that occludes the dura mater. ${ }^{9-10}$

Surgery is always proved to be the best management option. A few known methods of surgery have been utilized like craniotomy with single or twin burr holes with or without the use of irrigation and drainage system, and trephination with twist drill at the site of maximum hematoma thickness. ${ }^{11-12}$

Comorbid diseases are mostly encountered with CSDH that may have a poor impact on prognosis and postoperative outcome. In reality, mortality and morbidity along with re- accumulation of $\mathrm{CSDH}$ are somehow directly corelated with preoperative general condition and co-morbidities rather than direct influence or failure of surgery. The pace of recurrence of CSDH after the procedure is somewhere in the range of $3.7 \%$ and $30 \%{ }^{13-14}$

Dexamethasone has been chosen over methyl prednisone because of its independent body weight, longest biological half-life, and more power than prednisone, having good randomization and binding capacity, medication fixation in Cerebro Spinal Fluid CSF related with a key concentration in plasma. ${ }^{15}$

In this study, we used dexamethasone as a monotherapy in patients with recurrent or residual $\mathrm{CSDH}$, who had presented with Markwalder 0,1 and 2, with a thickness of hematoma less than $25 \mathrm{~mm}$ and midline shift less than $5 \mathrm{~mm}$ on Computed Tomography Scan (CT scan) of the brain. The effect of dexamethasone in these patients was vigilantly noticed and documented.

\section{MATERIAL AND METHODS}

\section{Study Design and Setting}

We conducted a descriptive type of study in the department of neurosurgery Peoples Medical College hospital Nawabshah from July 2014 to June 2020.

\section{Inclusion Criteria}

We included a patient with age above 15 years and Markwalder Neurological grading for $\mathrm{CSDH}$ $0,1, \& 2$, recurrent or residual unilateral or bilateral CSDH on plain CT scan of the brain with clot thickness of less than $25 \mathrm{~mm}$ and midline shift of less than $5 \mathrm{~mm}$, coagulation profile within normal limits, not willing for surgery and prefer to take dexamethasone trial.

\section{Exclusion Criteria}

We excluded patients age below 15 years, 
Markwalder grade3, \& 4, Clot thickness of more than $25 \mathrm{~mm}$, midline shift of more than $5 \mathrm{~mm}$, $\mathrm{CSDH}$ in the presence of VP Shunt, already on immunosuppressive and chemotherapeutic drugs, active variceal or rectal bleeding, active gastric ulcer, and uncontrolled diabetes mellitus.

\section{Data Collection Procedure}

For all patients with recurrent or residual chronic $\mathrm{SDH}$ admitted in the neurosurgery ward, Markwalder neurological grading was used to assess the clinical status of patients with recurrent or residual chronic SDH hematoma, and a plain CT scan of the brain was done to check the volume of hematoma and midline shift. An approval from the hospital ethical committee was received, close relatives were informed, counseled and written consent was obtained.

\section{Data Analysis}

Data were analyzed by using SPSS (Statistical Package for Social Services) version 20, mean and standard deviation, was calculated for numerical data like age. Categorical data like gender, clinical symptoms, complications, and comorbidities were presented as percentages and frequencies. Dexamethasone was started on the very first day of admission and the effect of management was assessed and documented on proforma from the first day of treatment.

\section{RESULTS}

\section{Age and Demographic Assessment}

Among 1000 cases chronic subdural hematoma was presented in 100 patients with recurrent and 180 patients had a residual chronic subdural hematoma (Figure 1). Out of 280 patients in which male patients were $64 \%$ and female were $36 \%$. With proportional ratio for a male to female was1.8:1 (Figure 2).

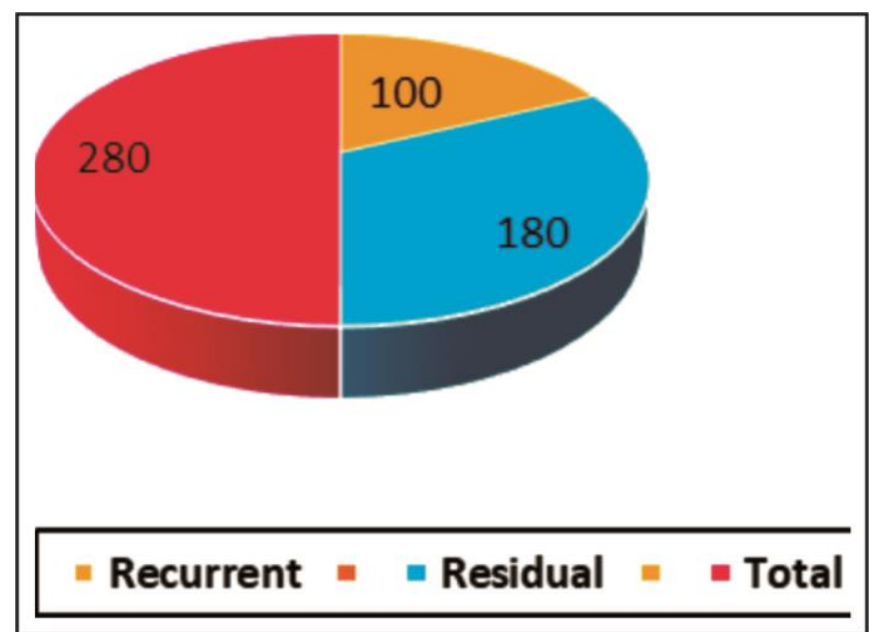

Figure 1: Total distribution of Chronic Subdural hematoma.

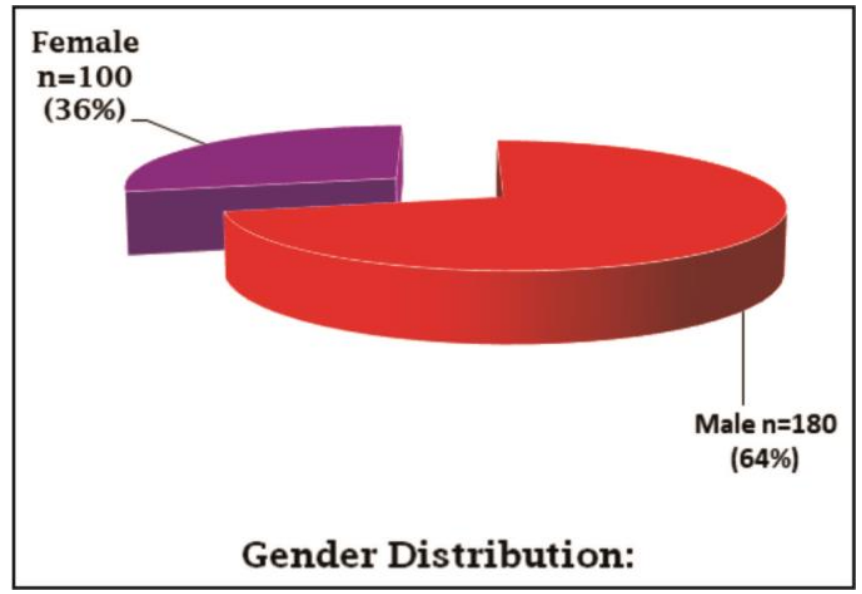

Figure 2: Gender distribution.

\section{Dexamethasone Treatment Protocol}

All patients were admitted to the neurosurgery department and monotherapy with dexamethasone of $12 \mathrm{mg}$ into three divided doses per 24 hours along with a cover of proton pump inhibitor of $40 \mathrm{mg}$ intravenous was given for first 7 days, next week $8 \mathrm{mg}$ dexamethasone into three divided doses with a cover of proton pump inhibitor of $40 \mathrm{mg}$ intravenous was given. Then shifted to oral dexamethasone $3 \mathrm{mg}$ per 24 hours into 3 divided doses for almost 2 weeks. During this period, the patient was evaluated for blood sugar and burning epigastric pain. During the first 2 weeks of dexamethasone intravenous 
therapy patient was kept in the neurosurgery ward, then discharged to home with instruction and regularly followed up as an outdoor on every week for up to 35 days was carried out. First Scan was done after 4 weeks. The patient's first followup was after 2 weeks, the second follow-up was after 4 weeks, and so on for up to 1 year.

\section{Comorbid Illness and Etiology}

In our study, $17.86 \%$ of patients were hypertensive, Ischemic Heart Disease (IHD) plus hypertension was in $14.29 \%$, Diabetes Mellitus was in $5.36 \%$ and hypertension with ischemic heart disease was in $5.36 \%$ of patients.

$7.14 \%$ were relatively younger, having a previous mild head injury and $3.57 \%$ with slipped over stairs. $42.86 \%$ were already on anti-clotting acetylsalicylic acid therapy and trivial trauma was found in $46.43 \%$ of patients.

\section{Clinical Follow-up and Radiological Assessment}

Out of 280 patients, $16.07 \%$ patient had Markwalder Grade -2 and $12.14 \%$ patients had Markwalder Grad - 1 with mini mal chronic SDH. Subsequently, $53.57 \%$ of patients with Markwalder Grade - 0 showed complete resolution of hematoma after 6 weeks. In 14.29\% of patients, the volume of chronic SDH increased in size and presented with marked midline shift with neurological worsening to Markwalder grade 3 in 15 and grade 4 in 25 patients, these patients were considered for reoperation (Table 1). While $28.57 \%$ of patients showed complete resolution of chronic SDH after 2 months and 25\% of patients showed complete resolution after 4 months which is evident on CT scans of the brain (Figures 3 and 4). After 2 weeks of surgery one patient developed left $3^{\text {rd }}$ nerve ptosis for an unknown reason and 3 patients had focal facial fits, which were controlled with an anticonvulsant.

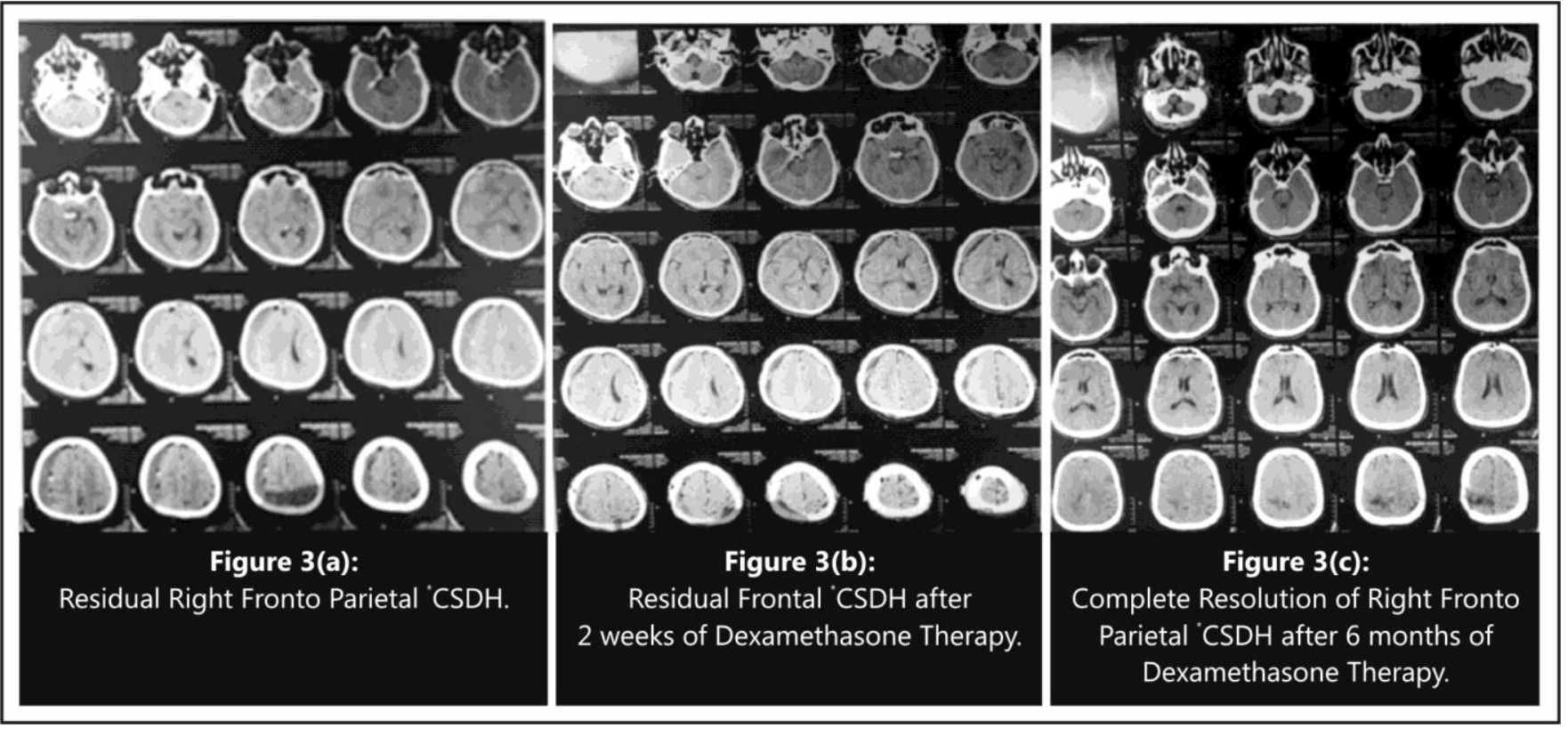

Figure 3: Pre and post Dexamethasone therapy images of frontoparietal CSDH*(chronic subdural hematoma). 


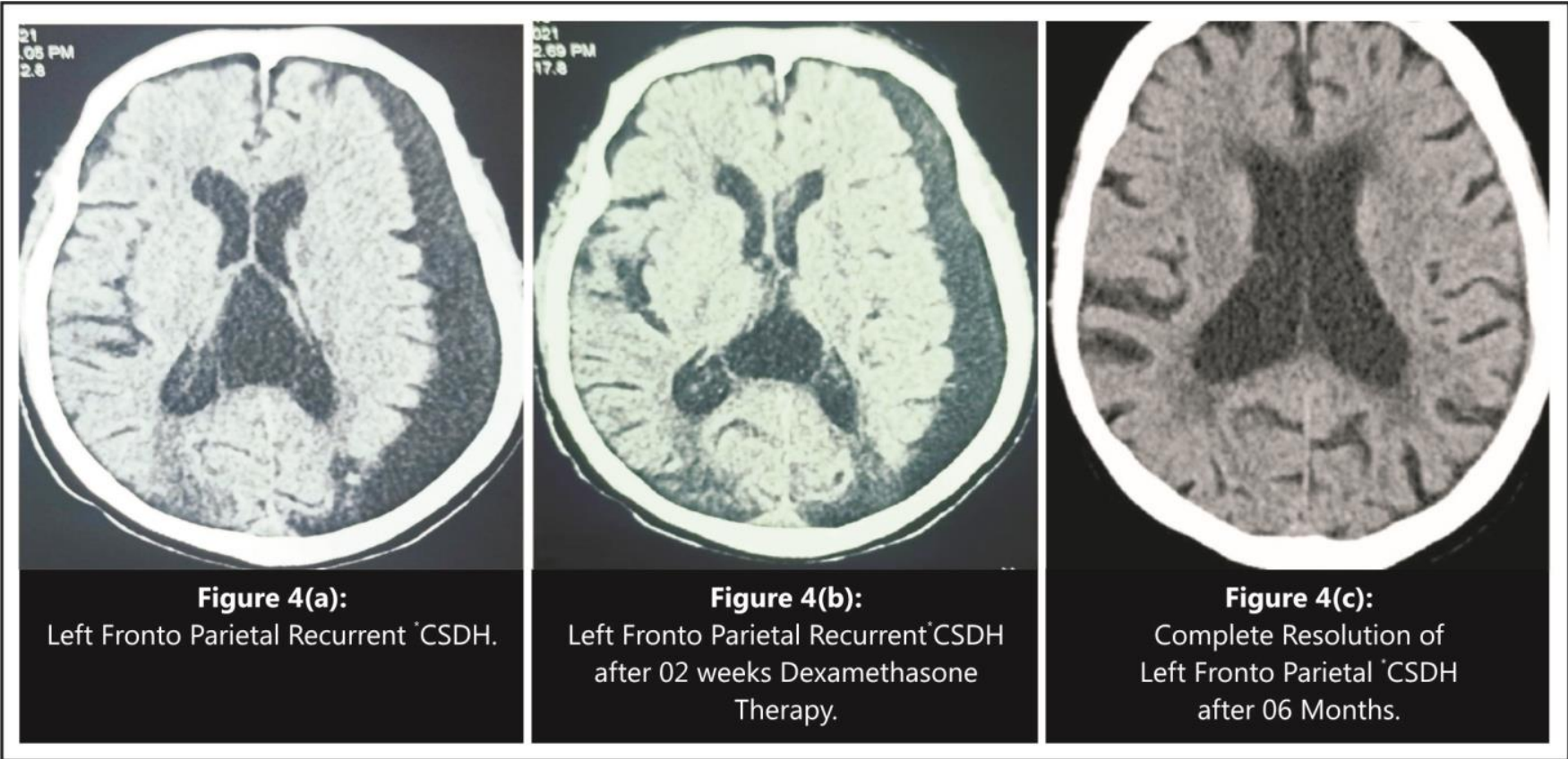

Figure 4: Before and after dexamethasone therapy images of left Front parietal CSDH *(chronic subdural hematoma).

Table 1: Markwalder neurological grading, radiological analysis follow up and outcome of chronic subdural hematoma with dexamethasone therapy.

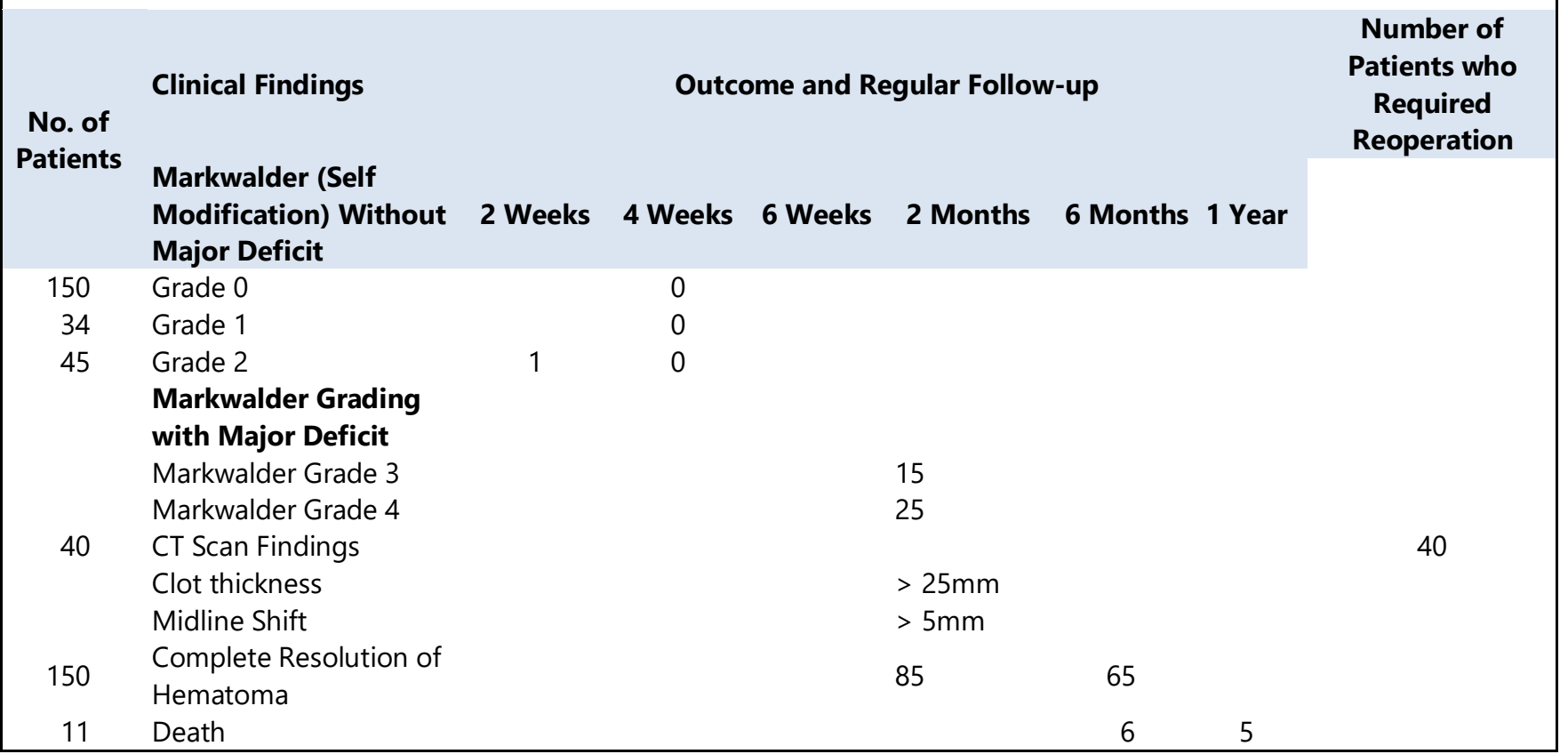


Table 2: Comparison of the present study with literature reviews.

\begin{tabular}{|c|c|c|c|c|c|c|c|}
\hline Study & $\begin{array}{c}\text { Total } \\
\text { Number } \\
\text { of } \\
\text { Patients }\end{array}$ & $\begin{array}{l}\text { Type and Dose } \\
\text { of Steroids }\end{array}$ & $\begin{array}{c}\text { Status of } \\
\text { Chronic } \\
\text { SDH }\end{array}$ & $\begin{array}{c}\text { Route of } \\
\text { Administration, } \\
\text { Duration/Tapering }\end{array}$ & $\begin{array}{c}\text { Neurological } \\
\text { Scale }\end{array}$ & Outcome & $\begin{array}{l}\text { Reoperat } \\
\text { ion }\end{array}$ \\
\hline $\begin{array}{l}\text { Present } \\
\text { Study }\end{array}$ & 280 & $\begin{array}{l}\text { Dexamethasone } \\
12 \mathrm{mg} \text { in } 3 \\
\text { divided doses } \\
\text { per day. }\end{array}$ & $\begin{array}{l}\text { Recurrent } \\
\text { Or } \\
\text { Residual }\end{array}$ & $\begin{array}{l}\text { Both Intravenous and } \\
\text { oral } \\
\text { 2-week duration } \\
\text { Tapered over } 2 \\
\text { weeks = total } 4 \text { weeks }\end{array}$ & $\begin{array}{l}\text { Markwalder } \\
\text { neurological } \\
\text { scale } 0,1,2,3\end{array}$ & $\begin{array}{l}\text { Favorable } \\
\text { outcome } \\
81.7 \% . \\
\text { Death } 3.9 \%\end{array}$ & $14.2 \%$ \\
\hline $\begin{array}{l}\text { Hutchisone } \\
\text { et al. } .^{20}\end{array}$ & 375 & $\begin{array}{l}\text { Dexamethasone } \\
8 \mathrm{mg} \text { twice a day }\end{array}$ & $\begin{array}{l}\text { The first } \\
\text { line of } \\
\text { therapy }\end{array}$ & $\begin{array}{l}\text { Oral } \\
2 \text { weeks }\end{array}$ & $\begin{array}{l}\text { Modified } \\
\text { Rankin scale } \\
1,2,3 .\end{array}$ & $\begin{array}{l}\text { Favorable } \\
\text { outcome } 82 \% \\
\text { Death } 8.8 \%\end{array}$ & $1.7 \%$ \\
\hline $\begin{array}{l}\text { Prud'homme } \\
\text { et al. }\end{array}$ & 10 & $\begin{array}{l}4 \mathrm{mg} \text { in } 3 \\
\text { divided doses }\end{array}$ & $\begin{array}{l}\text { First line of } \\
\text { therapy }\end{array}$ & $\begin{array}{l}\text { Oral } \\
3 \text { weeks }\end{array}$ & $\begin{array}{l}\text { Markwalder } \\
\text { grading } \\
0,1,2,3,4\end{array}$ & $\begin{array}{l}\text { Favorable } \\
\text { outcome } 60 \% \\
\text { Death } 20 \%\end{array}$ & $10 \%$ \\
\hline $\begin{array}{l}\text { Petralia } \\
\text { et al. }{ }^{22}\end{array}$ & 49 & $\begin{array}{l}4 \mathrm{mg} \text { and } \\
\text { variable dose } \\
\text { thrice a day }\end{array}$ & $\begin{array}{l}\text { The first } \\
\text { line of } \\
\text { therapy. } \\
\text { Duration } \\
\text { variable }\end{array}$ & $\begin{array}{l}\text { Route not } \\
\text { mentioned } \\
31 \text { days }\end{array}$ & Not mentioned & Not mentioned & $8.2 \%$ \\
\hline
\end{tabular}

\section{DISCUSSION}

Despite multimodality surgical options recurrent rate and incomplete evacuation of CSDH is fairly common. ${ }^{16}$ Due to anti-inflammatory, antiangiogenic, and pro-resorbing effects, corticosteroids are considered to be beneficial in the management of $\mathrm{CSDH} .{ }^{17}$

In our study, we used dexamethasone as a monotherapy in patients that were previously operated on and present with recurrent and residual $\mathrm{CSDH}$, because of the high rate of mortality and morbidity we did not consider corticosteroids as a primary monotherapy in patients with Markwalder grade III and IV, and clot thickness on plain CT scan of brain $>25 \mathrm{~mm}$ and midline shift $>5 \mathrm{~mm}$, these patients have a fairly high chance of brain herniation and fixed neuro deficit even death. The original Markwalder classification includes 0 , asymptomatic, 1 mild symptoms, 2 severe deficits, 3 stupors, 4 deeply comatose. $^{3}$

Surgery is the best option in such a condition. The first surgical treatment of $\mathrm{CSDH}$ with corticosteroid was mentioned by Ambrosetto in
$1958 .^{18}$

In 1962 first trial of Corticosteroid therapy was done in a cohort study of 85 patients with CSDH, 75 (40.01\%) were successfully managed with $60 \mathrm{mg}$ of dexamethasone enteral or parental therapy.

Dexamethasone therapy was used as an adjuvant to the post-surgical evacuation of CSDH. Various analytics studied managed chronic SDH conservatively with dexamethasone before putting burr hole, which had markedly reduced the rate of recurrence. ${ }^{7}$ Emich et al. reported that more than $50 \%$ of neurological surgeons in Northern Ireland and the United Kingdom, 13\% in Canada, $40 \%$ in France used corticosteroids postoperatively in $\mathrm{CSDH} .{ }^{19}$ The exact prevalence in the Pakistani population is not known because of the unavailability of online literature material.

A randomized multicenter study conducted in 2020 reported that the use of oral steroids may decrease the chance of reoperation but adverse effects are higher than the overall benefit. ${ }^{20}$ While in our study $81.7 \%$ had a favorable outcome, only $14.2 \%$ of patients were re-operated reason could 
be careful patient selection, while omitting severally disabled patients with a remarkable thick clot on CT scan of the brain.

Similarly, Prud'homme et al, had reported a favorable outcome of about $60 \%$ and fewer side effects along with less chance of reoperation about $10 \%$ in very small sample size and short doze of steroids. ${ }^{21}$

Casteno and others used steroids as a first line of therapy in all asymptomatic patients and they also found that the rate of re-surgery is quite low about $8.2 \%$ as compared to a conservative group, in contradicting they used variable doze of steroids and had not mentioned outcome. ${ }^{22}$

In our study we had found a remarkable reduction in the rate of reoperation, further its clear from various above mentioned research and other current studies, that chronic subdural hematoma when managed conservatively without steroids, mostly these patients end up had reoperation. ${ }^{23-24}$

In our observation, even reoperation was quite easier in patients who had taken steroids, due to fragile neo-membrane and lake of septaion, however, the overall chance of nonhealing wound may be fairly common. So maximum benefit of steroids could be achieved in chronic subdural hematoma when prescribed dose is moderate, given at a regular interval of about 8 hours under direct observation especially in patients who had mild symptoms, thin clot on CT scan of the brain.

\section{LIMITATIONS \& RECOMMENDATIONS}

Our study is of unique type as it only includes the patients who had recurrent or residual $\mathrm{CSDH}$ along with good Markwalder grade 0, 1, 2, and without evidence of marked herniation on CT scan radiology which favors good outcome. However further research work should be done on the pathophysiology of CSDH and use of other targeted monotherapy or adjuvant therapy along with steroids, statin drugs, tranexamic acid, non- steroidal anti-inflammatory drugs, osmotic therapy, Angiotensin converting enzyme inhibitors.

\section{CONCLUSION}

Utilization of corticosteroids therapy for recurrent and residual $\mathrm{CSDH}$ prove to be effective in patients with Markwalder 0, 1, 2, and midline shift less than 5. It markedly improved the neurological outcome, reduced the rate of mortality and morbidity especially in elderly patients and who refuse to re-operate. However, basic research that defines new pathways and mechanism of action of drugs that used for management of $\mathrm{CSDH}$ should be done at a higher level to target $\mathrm{CSDH}$.

\section{ACKNOWLEDGMENT}

Mr. Imran Ali, Computer Operator, in the Department of Neurosurgery, PUMHSW, Nawabshah has contributed to the completion of this article by rendering his services in grammar accuracy and typographical correction.

\section{Funding or Sponsorship}

Nil.

\section{REFERENCES}

1. Adhiyaman V, Asghar $M$, Ganeshram $\mathrm{KN}$, Bhowmick BK. Chronic subdural haematoma in the elderly. Postgrad Med J. 2002; 78 (916): 71-75.

2. Gelabert-Gonzalez M, Iglesias-Pais $M$, Garcia-Allut A, Martinez-Rumbo R. Chronic subdural haematoma: surgical treatment and outcome in 1000 cases. Clin Neurol Neurosurg. 2005; 107 (3): 223-229.

3. Markwalder TM, Steinsiepe KF, Rohner M, et al. The course of chronic subdural haematoma after burr-hole craniostomy and closed-system drainage. J Neurosurg. 1981; 55: 390-396.

4. Steimle R, Jacquet G, Godard J, Fahrat O, Katranji $\mathrm{H}$. Chronic subdural hematoma in the elderly and computerized tomography: study of 80 cases [in 
French]. Chirurgie. 1990; 116 (2): 160-167.

5. Nakaguchi $\mathrm{H}$, Tanishima $\mathrm{T}$, Yoshimasu N. Factors in the natural history of chronic subdural hematomas that influence their postoperative recurrence. J Neurosurg. 2001; 95: 256-262,

6. Goodell CL, Mealey J. Pathogenesis of chronic subdural hematoma. Experimental studies. Arch Neurol. 1963; 8: 429-437.

7. Berghauser Pont LM, Dammers R, Schouten JW, et al. Clinical factors associated with outcome in chronic subdural hematoma: a retrospective cohort study of patients on preoperative corticosteroid therapy. Neurosurgery, 2012; 70 (4): 873-880.

8. Park KS, Park SH, Hwang SK, Kim C. Hwang JH. Correlation of the Beta-Trace Protein and Inflammatory Cytokines with Magnetic Resonance Imaging in Chronic Subdural Hematomas: A Prospective Study. J. Korean Neurosurg. 2015; 57: 235-241.

9. Hirasima $\mathrm{Y}$, Endo $\mathrm{S}$, Hayashi $\mathrm{N}$, et al. Plateletactivating factor (PAF) and the formation of chronic subdural haematoma. Measurement of plasma PAF levels and anti-PAF immunoglobulin titers. Acta Neurochir. 1995; 137: 15-18.

10. Weigel R, Schilling L, Schmiedek P: Specific pattern of growth factor distribution in chronic subdural hematoma (CSH): evidence for an angiogenic disease. Acta Neurochir. 2001; 143: 811-819.

11. Okada $Y$, Akai T, Okamoto $K$, et al. A comparative study of the treatment of chronic subdural hematoma-burr hole drainage versus burr hole irrigation. Surg Neurol. 2002; 57: 405-410.

12. Kwon TH, Park YK, Lim DJ, et al. Chronic subdural hematoma: evaluation of the clinical significance of postoperative drainage volume. J Neurosurg. 2000; 93: 796-799.

13. Tanikawa $M$, Mase $M$, Yamada $K$, et al. Surgical treatment of chronic subdural hematoma based on intrahematomal membrane structure on MRI. Acta Neurochir. 2001; 143: 613-619.

14. Reinges $\mathrm{MH}$, Hasselberg I, Rohde $\mathrm{V}$, et al. Prospective analysis of bedside percutaneous subdural tapping for the treatment of chronic subdural haematoma in adults. J Neurol Neurosurg Psychiatry, 2000; 69: 40-47.

15. Mebberson K, Colditz M, Marshman LAG, et al. Prospective randomized placebo-controlled double-blind clinical study of adjuvant dexamethasone with surgery for chronic subdural haematoma with post-operative subdural drainage: interim analysis. J Clin Neurosci. 2019; S0967-5868 (19): 31364-5.

16. Brennan PM, Kolias AG, Joannides $A J$, et al. The management and outcome for patients with chronic subdural hematoma: a prospective, multicenter, observational cohort study in the United Kingdom. J Neurosurg, 2017: 1-7.

17. Robinson RG. Chronic subdural hematoma: surgical management in 133 patients. J Neurosurg. 1984; 61: 263-268.

18. Ambrosetto, C. Osservazioni Sul Trattamento Dell'ematoma Subdurale Cronico Post-traumatico, Sist. Nerv. 1958; 10: 435.

19. Emich S, Richling $B, M c$ Coy MR, Al-Schameri RA, Ling $F$, Sun $L$, et al. The efficacy of dexamethasone on reduction in the reoperation rate of chronic subdural hematoma-the DRESH study: straightforward study protocol for a randomized controlled trial. Trials, 2014; 6 (15): 6.

20. Hutchinson PJ, Edlmann E, Bulters D, Zolnourian A, Holton $P$, et al. Trial of Dexamethasone for Chronic Subdural Hematoman. Engl J Med. 2020.

21. Prud'homme M, Mathieu F, Marcotte N, Cottin S. A pilot placebo controlled randomized trial of dexamethasone for chronic subdural hematoma. Canadian Journal of Neurological Sciences, 2016; 43 (2): 284-90.

22. Cateno Concetto Tito Petralia, Susruta Manivannan, Dmitri Shastin et al. Effect of Steroid Therapy on Risk of Subsequent Surgery for Neurologically Stable Chronic Subdural Hemorrhage-Retrospective Cohort Study and Literature Review. J Elesvier; World Neurosurg. 2020; 138: e35-e41.

23. Holl DC, Volovici V, Dirven CMF, et al. Corticosteroid treatment compared with surgery in chronic subdural hematoma: a systematic review and meta-analysis. Acta Neurochir (Wien), 2019; 161: 1231-1242.

24. Qian Z, Yang D, Sun F, Sun Z. Risk factors for recurrence of chronic subdural hematoma after burrhole surgery: potential protective role of dexamethasone. Br J Neurosurg. 2017; 31: 84-88. 


\section{Additional Information}

Disclosures: Authors report no conflict of interest.

Ethical Review Board Approval: The study was conformed to the ethical review board requirements.

Human Subjects: Consent was obtained by all patients/participants in this study.

Conflicts of Interest:

In compliance with the ICMJE uniform disclosure form, all authors declare the following:

Financial Relationships: All authors have declared that they have no financial relationships at present or within the previous three years with any organizations that might have an interest in the submitted work.

Other Relationships: All authors have declared that there are no other relationships or activities that could appear to have influenced the submitted work.

\section{AUTHORS CONTRIBUTIONS}

\begin{tabular}{|l|l|l|}
\hline Sr.\# & Author's Full Name & Intellectual Contribution to Paper in Terms of: \\
\hline 1. & Syed Aamir Shah & Paper writing, referencing, and data calculations. \\
\hline 4. & Fahmida Arab Mallah & Data collection and calculations. \\
\hline 2. & Abdul Razaque Mari & Study design and methodology. \\
\hline 3. & Imran Mirbahar & Analysis of data and interpretation of results. \\
\hline 5. & Hamid Akbar Shaikh & Literature review and manuscript writing. \\
\hline 6. & Muzamil Dilber & Analysis of data and quality insurer. \\
\hline 7. & Shams Raza Brohi & Article Review and Supervision \\
\hline
\end{tabular}

